\title{
PENGARUH JARAK ANTAR TIANG TERHADAP EFISIENSI DAYA DUKUNG TIANG KELOMPOK BOR
}

\author{
Robert $S^{1}$ dan Gregorius Sandjaja Sentosa ${ }^{2}$ \\ ${ }^{1}$ Program Studi Sarjana Teknik Sipil, Universitas Tarumanagara, Jl. Letjen S. Parman No.1 Jakarta \\ robertsang1825@gmail.com \\ ${ }^{2}$ Program Studi Sarjana Teknik Sipil, Universitas Tarumanagara, Jl. Letjen S. Parman No.1 Jakarta \\ gregoriuss@ft.untar.ac.id
}

Masuk: 11-02-2021, revisi: 05-02-2021, diterima untuk diterbitkan: 17-02-2021

\begin{abstract}
The main purpose of this journal is to determine the effective pile spacings. In this study, the foundation design is bored pile group $3 \times 3$ with length $12 \mathrm{~m}$ and diameter $0,6 \mathrm{~m}$. The load capacity of a pile group is depends on pile spacings. Therefore, the spacings that is used in this thesis is $1,7 D ; 2 D ; 2,5 D ; 3 D ; 4 D ; 5 D ; 6 D$. To determine the efficiency of a pile group with varying spacings, calculations are made using 10 methods. From the results of the calculation of the efficiency, the most relative effective pile spacings are determined. The results show 2,5D spacing is the most relative effective for bored pile group with diameter $0,6 \mathrm{~m}$ and length $12 \mathrm{~m}$ has most relative effective spacing 2,5D.
\end{abstract}

Keywords: pile foundation, pile spacing, efficiency, pile group.

\begin{abstract}
ABSTRAK
Tujuan utama dari penulisan jurnal ini adalah untuk menentukan jarak tiang yang efektif. Pada penelitian kali ini, digunakan jenis fondasi kelompok tiang bor 3x3 dengan panjang $12 \mathrm{~m}$ dan diameter 0,6m. Kapasitas dukung sebuah fondasi tiang kelompok tergantung pada jarak tiang yang ditentukan. Oleh karena itu, ditentukan pemasangan jarak tiang sebesar 1,7D ; 2D ; 2,5D ; 3D ; 4D ; 5D ; 6D. Untuk mendapatkan nilai efisiensi dari kelompok tiang dengan jarak yang bervariasi tersebut dilakukan perhitungan menggunakan 10 metode. Dari hasil perhitungan nilai efisiensi tersebut kemudian ditentukan jarak tiang yang relatif paling efektif untuk kelompok tiang. Hasil analisi menunjukkan bahwa tiang bor dengan diameter $0,6 \mathrm{~m}$ dan panjang $12 \mathrm{~m}$ memiliki jarak tiang yang relatif paling efektif sebesar 2,5D.
\end{abstract}

Kata kunci: fondasi tiang, jarak tiang , efisiensi , kelompok tiang.

\section{PENDAHULUAN}

Pada umumnya semua rekayasa konstruksi dibagi menjadi dua bagian yaitu struktur atas (upper structure) dan struktur bawah (sub structure). Struktur bawah berupa fondasi yang dapat menyalurkan beban dari struktur atas menuju tanah. Stabilitas suatu bangunan sangat dipengaruhi oleh fondasi , bangunan dapat stabil apabila tanah dapat mendukung beban dari fondasi.

Setiap fondasi dituntut untuk dapat menerima beban yang diberikan , termasuk apabila beban maksimum terjadi. Beberapa jenis fondasi dapat digunakan tergantung pada struktur dan jenis tanah. Apabila tanah di dekat permukaan dapat mendukung beban struktur maka jenis fondasi dangkal yang berupa fondasi telapak (spread footing) dan fondasi rakit (raft foundation) dapat digunakan. Apabila tanah di dekat pemukaan tidak dapat mendukung beban struktur di atasnya, fondasi sumuran/kaison (pier foundation/caisson) dan fondasi tiang (pile foundation) dapat digunakan.

Jenis tanah yang berbeda menentukan cara perhitungan kapasitas daya dukung yang berbeda juga. Kapasitas daya dukung tiang kelompok bor dipengaruhi oleh efisiensi akibat jarak tiang. Menentukan jarak tiang juga dipengaruhi oleh beberapa faktor , seperti fungsi tiang, klasifikasi tanah, dan beberapa peraturan bangunan setiap daerah. Untuk menghitung nilai efisiensi dapat digunakan beberapa metode perhitungan. Pada penelitian kali ini, penulis akan membandingkan nilai efisiensi dari beberapa metode tersebut untuk menentukan metode perhitungan yang relatif paling efektif dalam menghitung nilai efisiensi. Dalam jurnal ini juga akan dibandingkan dengan pemodelan finite element menggunakan program Midas GTS NX. Dari tinjauan pendahuluan , penulis mencoba untuk mempelajari serta menganalisis tentang "Pengaruh jarak antar tiang terhadap efisiensi daya dukung kelompok tiang bor". 


\section{TEORI KELOMPOK TIANG}

Dalam perhitungan efisiensi kelompok tiang, diawali dengan perhitungan daya dukung tiang tunggal yang menggunakan beberapa macam rumus yang didapatkan dari parameter laboratoirum atau lapangan.

\section{Perhitungan daya dukung tiang tunggal}

Sebelum melakukan perhitungan analisis fondasi , diperlukan perencanaan estimasi beban bangunan total yang nantinya akan diteruskan ke fondasi. Untuk mendapatkan besar daya dukung fondasi tiang bor dapat dilakukan dengan menggunakan rumus umum yang didapat dari akumulasi tahanan ujung dan tahanan selimut tiang. Rumus umum dapat dinyatakan dalam bentuk (Rahardjo, 2013) :

$$
\mathrm{Q}_{\mathrm{u}}=\frac{\mathrm{Q}_{\mathrm{p}}+\mathrm{Q}_{\mathrm{s}}}{\mathrm{SF}}
$$

dimana $\mathrm{Q}_{\mathrm{u}}$ = daya dukung ultimit, $\mathrm{Q}_{\mathrm{p}}=$ daya dukung ujung, $\mathrm{Q}_{\mathrm{s}}=$ daya dukung selimut dan $\mathrm{SF}=$ faktor keamanan.

Untuk mendapatkan nilai $\mathrm{Q}_{\mathrm{p}}$ (daya dukung ujung) maka dapat digunakan persamaan berikut:

$$
\mathrm{Q}_{\mathrm{p}}=9 . \mathrm{Su} \cdot A
$$

dengan $\mathrm{Q}_{\mathrm{p}}=$ daya dukung ujung, $\mathrm{Su}=$ undrained shear strength dan $\mathrm{A}=$ luas penampang tiang.

Untuk mencari nilai $\mathrm{Q}_{\mathrm{s}}$ (daya dukung selimut) dapat digunakan persamaan berikut:

$$
\mathrm{Q}_{\mathrm{s}}=\alpha \cdot \mathrm{Cu} \cdot \mathrm{L} \cdot \mathrm{p}
$$

dengan $\alpha=$ faktor adhesi, $\mathrm{Cu}=$ kohesi tanah, $\mathrm{L}=$ panjang tiang dan $\mathrm{p}=$ keliling penampang tiang.

\section{Efisiensi tiang kelompok}

Jika pile cap yang dipasang sudah sesuai persyaratan , maka kapasitas daya dukung tiang tunggal bukan hanya dikalikan dengan banyak tiang , tapi harus dikalikan lagi dengan nilai efisiensi kelompok tiang. Efisiensi kelompok tiang dapat didefinisikan sebagai :

$$
\mathrm{E}_{\mathrm{g}}=\frac{\text { daya dukung kelompok tiang }}{\text { jumlah tiang } \mathrm{x} \text { daya dukung tiang tunggal }}
$$

Formula - formula yang dapat digunakan untuk melakukan perhitungan efisiensi tiang antara lain (Rahardjo) :

Formula Das (Rahardjo, 2013)

$$
\mathrm{E}_{\mathrm{g}}=\frac{2(\mathrm{~m}+\mathrm{n}-2) \mathrm{s}+4 \mathrm{D}}{\mathrm{p} \cdot \mathrm{m} \cdot \mathrm{n}}
$$

dimana $\mathrm{E}_{\mathrm{g}}=$ efisiensi, $\mathrm{m}=$ jumlah tiang pada deret baris, $\mathrm{n}=$ jumlah tiang pada deret kolom, $\mathrm{s}=$ jarak pusat tiang, $\mathrm{D}$ = diameter tiang, $\mathrm{p}=$ keliling penampang tiang.

Formula Converse - Labarre (Rahardjo, 2013)

$$
\mathrm{E}_{\mathrm{g}}=1-\left[\frac{(n-1) m+(m-1) n}{90 \cdot \mathrm{m} \cdot \mathrm{n}}\right] \arctan \mathrm{D} / \mathrm{s}
$$

dimana Eg = efisiensi, $\mathrm{m}=$ jumlah tiang pada deret baris, $\mathrm{n}=$ jumlah tiang pada deret kolom, $\mathrm{s}=$ jarak pusat tiang, $\mathrm{D}$ $=$ diameter tiang.

Formula Los Angeles (Rahardjo, 2013)

$$
E_{g}=1-\frac{D}{\pi \cdot s \cdot m \cdot n}[m(n-1)+n(n-1)+(m-1)(n-1) \sqrt{2}]
$$

dimana Eg = efisiensi, $\mathrm{m}=$ jumlah tiang pada deret baris, $\mathrm{n}=$ jumlah tiang pada deret kolom, $\mathrm{s}=$ jarak pusat tiang, $\mathrm{D}=$ diameter tiang.

Formula Seiler - Keeney (Rahardjo, 2013)

$$
E_{g}=\left[1-\frac{36 s(m+n-2)}{\left(75 s^{2}-7\right)(m+n-1)}\right]+\frac{0,3}{m+n}
$$

\section{Formula Feld (Rahardjo, 2013)}

Pada metode ini kapasiatas pondasi individual tiang berkurang 1/16 akibat adanya tiang yang berdampingan dalam arah lurus ataupun diagonal. 


\section{Solusi Teori Elastis (Poulos and Davis, 1974)}

Pada metode ini, kondisi tanah dan tiang dianggap dalam kondisi elastis. Untuk mendapatkan nilai efisiensi, dihitung tegangan pada selimut tiang serta ujung tiang serta penambahan tegangan oleh beban yang bekerja pada tiang lain, lalu jumlah tengan tersebut dibandingkan dengan beban yang bekerja di atas tiang. Untuk menghitung tegangan yang terjadi pada titik tertentu dapat menggunakan rumus (Poulos and Davis, 1974):

$$
\begin{aligned}
\sigma_{\mathrm{z}} & =\frac{3 \mathrm{Pz}^{3}}{2 \pi \mathrm{R}^{5}} \\
\mathrm{E}_{\mathrm{g}}=\frac{\mathrm{P}}{\sum \sigma \mathrm{z}} &
\end{aligned}
$$

dimana koefisien-koefisien pada rumus di atas disesuaikan dengan gambar berikut.

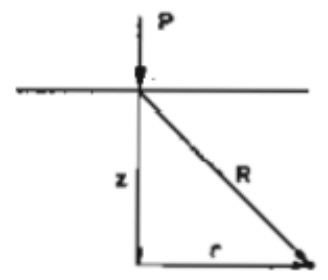

Gambar 1. Ilustrasi Tegangan Pada Titik Tertentu (Poulos \& Davis, 1974)

\section{Formula Poulos (Poulos and Davis, 1974)}

$$
\eta=\frac{1}{8} \mathrm{~d} / \mathrm{s}
$$

dimana $\eta=$ efisiensi, $d=$ diameter tiang, $s=$ jarak pusat tiang.

\section{Metode Thomas Whitaker (Poulos and Davis, 1974)}

Pada metode ini, Thomas Whitaker mengusulkan grafik yang dapat mempermudah penentuan nilai efisiensi dari kelompok tiang.

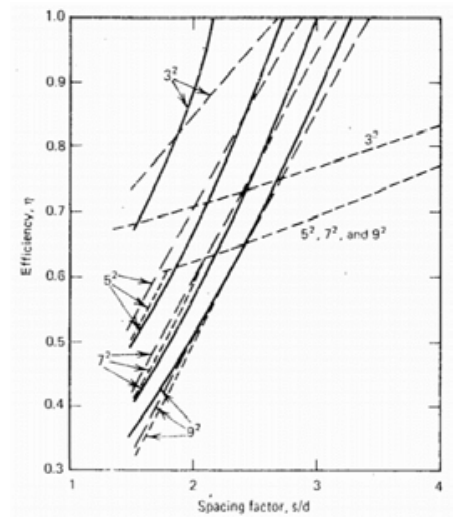

Gambar 2. Efisiensi pada Kelompok Tiang (Whitaker, 1970)

\section{Metode Terzaghi \& Peck (Poulos and Davis, 1974)}

Pertama kita menentukan kapasitas ultimit dari sebuah blok menggunakan rumus:

$$
\mathrm{P}_{\mathrm{B}}=\mathrm{B}_{\mathrm{r}} \mathrm{L}_{\mathrm{r}} \mathrm{N}_{\mathrm{c}}+2\left(\mathrm{~B}_{\mathrm{r}}+\mathrm{L}_{\mathrm{r}}\right) \mathrm{Lc}
$$

Lalu digunakan rumus yang telah ditentukan oleh Terzaghi \& Peck untuk menentukan nilai efisiensi yaitu: 


$$
\frac{1}{\eta^{2}}=1+\frac{\mathrm{n}^{2} \mathrm{P} 1^{2}}{\mathrm{~PB}^{2}}
$$

\section{STUDI KASUS EFISIENSI KELOMPOK TIANG}

Untuk melakukan analisis kelompok tiang, diambil kasus yang telah ditulis oleh Anh Tuan (2016). Kasus yang dibahas berupa perbandingan nilai efisiensi menggunakan beberapa formula pada tanah granular.

Analisis yang dilakukan oleh Anh Tuan adalah kasus kelompok tiang dengan konfigurasi 9 tiang bor dengan ukuran diameter tiang bor 0,6 $\mathrm{m}$ dan panjang $12 \mathrm{~m}$. Dalam kasus yang dibahas tersebut kondisi tanahnya berupa tanah granular. Dalam tulisan tersebut, disimpulkan bahwa peneliti tersebut menentukan formula baru yang mirip dengan metode Sayed dan Bakeer untuk efisiensi kelompok tiang pada tanah granular. Pada analisis kali ini, penulis mengembangkan penelitian dari Anh Tuan dengan menambahkan metode perhitungan efisiensi menggunakan program finite element dan dengan teori elastisitas.

Pada penelitian ini, properti material tanah dan fondasi tiang yang akan digunakan mengacu pada jurnal “ $A$ Simplified Formular For Analysis Group Efficiency of Piles in Granular Soil.” yang ditulis oleh Anh Tuan. Kemudian parameter serta konfigurasi dari tiang kelompok 3x3 juga mengacu pada jurnal tersebut.

Berdasarkan data-data yang sudah dimiliki, pertama dilakukan perhitungan beban yang akan diberikan pada setiap tiang. Perhitungan beban dilakukan dengan menentukan daya dukung ultimit dari sebuah tiang. Setelah itu, data-data tanah dan konfigurasi tiang tadi dimasukkan ke dalam program Midas GTS NX 3D untuk mendapatkan hasil tegangan yang bekerja pada setiap tiang. Kemudian jumlah tegangan yang bekerja pada satu tiang dibandingkan dengan beban yang bekerja pada tiang tersebut untuk mendapatkan nilai efisiensi dari tiang tersebut.
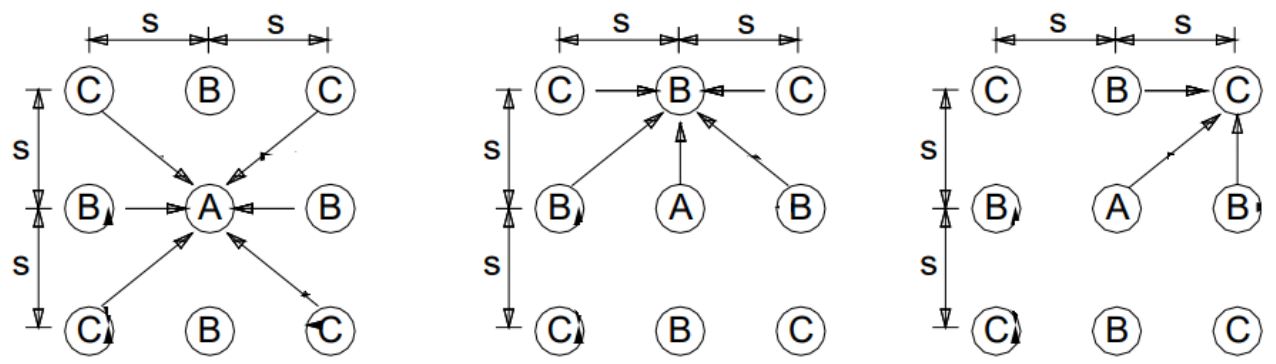

Gambar 3. Penamaan Tiang yang Menerima Tegangan Sama (Tuan, 2016)

Selain menggunakan program Midas GTS NX 3D, dilakukan juga perhitungan manual menggunakan solusi teori elastis oleh Poulos \& Davis untuk menentukan jumlah tegangan sepanjang tiang dan membandingkannya dengan beban yang bekerja di atasnya untuk mendapatkan nilai efisiensi dari tiang tersebut. Kemudian dilakukan juga perhitungan nilai efisiensi menggunakan rumus yang telah ditetapkan oleh para ahli. Nilai efisiensi yang telah didapat di atas kemudian diplot ke dalam grafik untuk menentukan jarak antar tiang yang relatif paling efektif.

\section{KAJIAN DAN HASIL PERBANDINGAN STUDI KASUS}

Nilai Efisiensi menggunakan perhitungan dari beberapa metode kemudian dimasukkan ke dalam tabel untuk melihat perbandingan hasilnya. Perbandingan nilai efisiensi dari beberapa metode dapat dilihat pada tabel 1. 
Tabel 1. Perbandingan nilai efisiensi dari beberapa metode

\begin{tabular}{ccccc}
\hline Metode & $1,7 \mathrm{D}$ & $2 \mathrm{D}$ & $2,5 \mathrm{D}$ & $3 \mathrm{D}$ \\
\hline Formula Das & 0,6222 & 0,7071 & 0,8485 & 0,9899 \\
Converse - Labarre & 0,5486 & 0,6064 & 0,6770 & 0,7268 \\
Los Angeles & 0,6328 & 0,6878 & 0,7503 & 0,7919 \\
Seiler - Keeney & 0,6364 & 0,7078 & 0,7829 & 0,8303 \\
Formula Feld & 0,7222 & 0,7222 & 0,7222 & 0,7222 \\
Teori Elastis & 0,6664 & 0,7231 & 0,8265 & 0,9298 \\
Midas GTS NX & 0,6851 & 0,7336 & 0,8479 & 1,0671 \\
Poulos & 0,2125 & 0,25 & 0,3125 & 0,375 \\
Thomas Whitaker & 0,79 & 0,81 & 0,95 & 1,05 \\
Terzaghi \& Peck & 0,6275 & 0,7162 & 0,8189 & 0,8849 \\
\hline
\end{tabular}

Hasil perhitungan untuk jarak tiang 4D, 5D, 6D tidak ditampilkan ke dalam tabel perbandingan nilai efisiensi karena hasil dari beberapa metode sudah menunjukkan angka yang lebih dari 1 sehingga tidak terlalu efektif untuk digunakan dalam pemasangan jarak tiang. Hasil analisis di atas diplot ke dalam grafik untuk menentukan jarak pusat tiang yang relatif paling efektif untuk tiang kelompok 3x3 dengan diameter 0,6m dan panjang 12m.

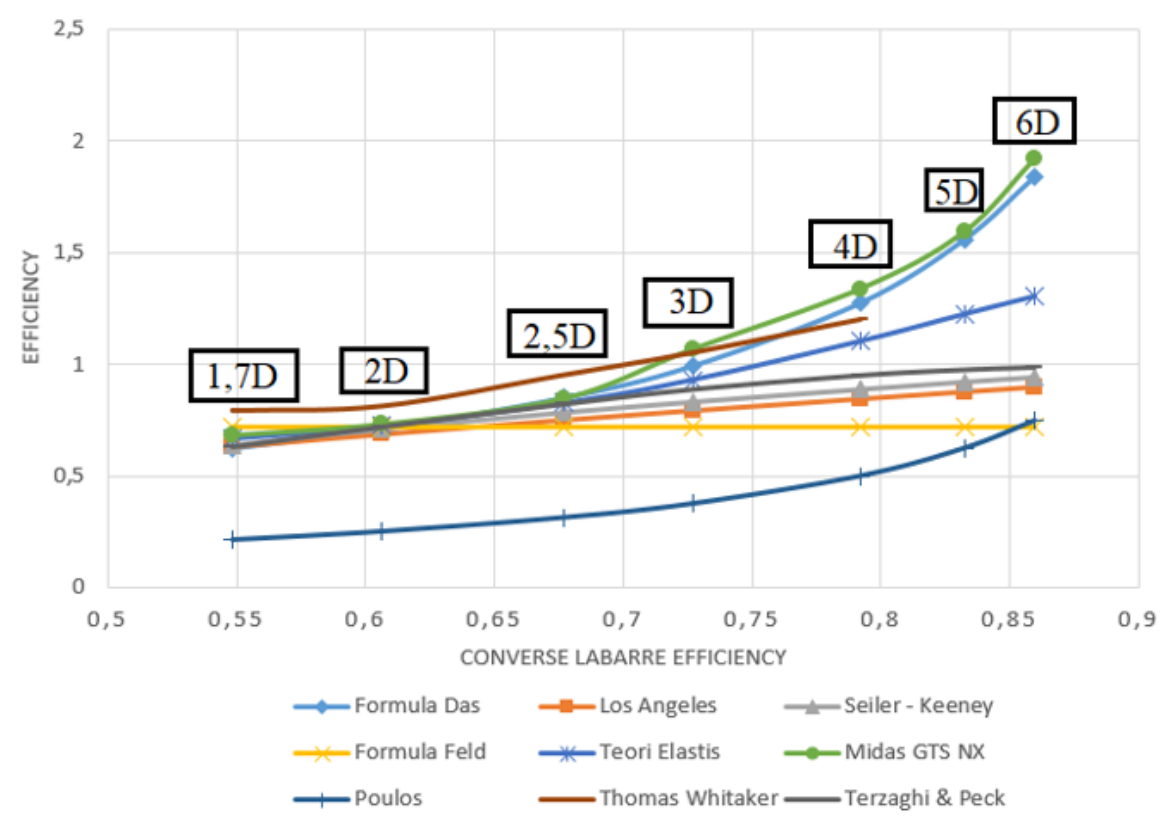

Gambar 4.

Berdasarkan grafik di atas, untuk tiang kelompok dengan jarak 1,7D memiliki rentang nilai efisiensi yang kecil sedangkan pada jarak 6D, rentang nilai efisiensi semakin besar. Perbedaan nilai efisiensi yang besar tersebut terjadi karena menurut beberapa metode, ketika jarak tiang lebih besar dari 3D, tiang-tiang tersebut sudah tidak bekerja sebagai sebuah kelompok. Jarak tiang yang paling efektif berdasarkan penelitian ini adalah 2,5D karena nilai efisiensi yang didapat dari beberapa metode menunjukkan angka yang paling mendekati nilai 1 yaitu sebesar 0,95. Pada jarak 1,7D sampai dengan 2,5D disarankan untuk dapat menggunakan semua metode kecuali metode Thomas Whitaker dan Poulos karna nilai metode tersebut tidak terlalu mirip dengan hasil metode lainnya. 


\section{KESIMPULAN DAN SARAN}

\section{Kesimpulan}

Dari studi kelompok tiang 3x3 dengan diameter 0,6m dan panjang 12m menggunakan beberapa metode untuk menetapkan nilai efisiensi:

1. Berdasarkan hasil perhitungan manual dan program Midas 3D, semakin besar jarak antar tiang, semakin besar pula rentang nilai efisiensi dari beberapa metode.

2. Pada jarak tiang 1,7D sampai dengan 2,5D memiliki rentang nilai efisiensi yang hasilnya hampir sama. Nilai efisiensi terkecil dapat dilihat ketika jarak antar pusat tiang berada pada jarak 1,7D, dengan nilai 0,55 dan nilai efisiensi terbesar pada jarak 2,5D dengan nilai 0,95.

3. Perhitungan nilai efisiensi menggunakan program MIDAS 3D menghasilkan angka yang relatif paling besar dibandingkan dengan perhitungan menggunakan metode yang lainnya.

4. Perhitungan nilai efisiensi menggunakan metode Converse-Labarre, Los Angeles dan Seiler-Keeney tidak ada yang melewati angka 1 sedangkan pada metode Das, teori elastis dan MIDAS 3D ada nilai efisiensi yang melewati angka 1 untuk jarak 4D, 5D dan 6D sehingga tidak dianjurkan untuk menggunakan jarak tiang tersebut.

5. Berdasarkan hasil penelitian, disarankan untuk memilih nilai efisiensi yang memiliki angka yang mirip yaitu untuk pemasangan jarak pusat tiang sebesar 1,7D , 2D dan 2,5D dapat menggunakan semua metode kecuali metode Thomas Whitaker dan Poulos karena nilainya yang tidak mirip dengan metode lainnya, sedangkan untuk jarak 3D, 4D, 5D, 6D menggunakan metode Los Angeles, Seiler-Keeney dan Terzahi-Peck.

\section{Saran terhadap penelitian selanjutnya}

Berdasarkan analisis yang telah dilakukan, dapat dianjurkan beberapa saran sebagai berikut:

1. Dalam perhitungan menggunakan program Midas, sebaiknya digunakan size mesh yang lebih kecil sehingga didapatkan hasil analisis yang lebih akurat.

2. Perlu studi lebih lanjut dengan menggunakan konfigurasi kelompok tiang dengan baris yang tidak beraturan untuk mendapatkan hasil yang lebih akurat untuk nilai efisiensi.

\section{DAFTAR PUSTAKA}

Poulos, Harry George and Edward Hughesdon Davis. Elastic Solutions For Soil And Rock Mechanics. New York: John Wiley \& Sons, Inc., 1974.

Rahardjo, Paulus P. Manual Pondasi Tiang. Bandung: Universitas Parahyangan, 2013.

Tuan, PHAM Ang. “A Simplified Formular For Analysis Group Efficiency of Piles in Granular Soil.” International Journal of Scientific \& Engineering Research (2016).

Whitaker, Thomas. The Dsign of Pile Foundations. Oxford: Pergamon, 1970. 